\title{
Família, Gênero e Emancipação Psicossocial
}

\author{
André Masao Peres Tokuda \\ Universidade Estadual Paulista Júlio de Mesquita \\ Filho, SP, Brasil. \\ Universidade Estadual Paulista Júlio de Mesquita \\ Filho, SP, Brasil. \\ Caio Andrêo \\ Universidade Estadual Paulista Júlio de Mesquita \\ Filho, SP, Brasil.
}

\begin{abstract}
Resumo: $\mathrm{O}$ contemporâneo aponta crises de paradigmas que solicitam mudanças conceituais nas composições familiares, em suas relações e estratégias de poder. Estas mudanças atingem principalmente as mulheres, porém, ainda ocorrem diversos modos de violências contra elas, como as de gênero. Estas análises se mostram presentes na experiência de estágio curricular em Psicologia Clínica, realizada em uma vila periférica por graduando(a)s de Psicologia. Este cenário aponta para regulações e controles sobre os corpos, sexos, sexualidade, gênero e práticas relacionais dentro da própria família, na qual ainda se mantêm estilos de vida restritos a padrões heteronormativos que excluem outros arranjos possíveis de composições familiares e relacionais. Desta forma, queremos problematizar as diversas experiências que despotencializam as mulheres, e também propor uma Psicologia Política de promoção dos direitos sexuais e humanos que contemplem uma vida em que as pessoas possam ter seus desejos e singularidades respeitadas, para que alcancem emancipação psicossocial e tenham acesso à cidadania.
\end{abstract}

Palavras-chave: Gênero, Família, Psicologia Clínica, Psicologia Social.

\section{Family, Gender and Psychosocial Emancipation}

Abstract: Modern times point out paradigm crisis that require conceptual changes in the compositions family, their relationships and power strategies. These modifications affect women in particular, however, there are other several kinds of violence versus women, among them, the ones related to gender. These analysis were studied during the Clinic Psychology curricular apprenticeship, which took place in a suburb, by Psychology undergraduates. This panorama points out to regulations and control over ones' bodies, sexes, genders, sexualities and other related practices inside their own family, in which heteronormative standards are still kept and other possible types of family formations and relations are excluded. This way we want to problematize the different thoughts that disempower women, and, moreover, the conception of a Political Psychology to promote sexual and human rights, enabling people to find out their own desires and singularities and leading them to social emancipation.

Keywords: Gender, Family, Clinical Psychology, Social Psychology. 


\title{
Familia, Género y la Emancipación Psicosocial
}

\begin{abstract}
Resumen: Los tiempos modernos señalan crisis de paradigma que requiere cambios conceptuales en la familia, sus relaciones de poder. Estas modificaciones afectan mujeres en particular, sin embargo, hay otros varios tipos de violencia contra las mujeres, las relacionadas con el género. Estos análisis se estudiaron durante el aprendizaje curricular en Psicología Clínica, por los estudiantes de Psicología. Este panorama apunta el control sobre los cuerpos, géneros, sexualidade y otras prácticas relacionadas dentro de propia familia, en el que las normas heteronormativas todavía se mantienen y otros posibles tipos de formaciones de la familia y las relaciones son excluidos. De esta manera queremos problematizar los pensamientos que discapacitan a las mujeres, y, por otra parte, la concepción de una Psicología Política promotora los derechos sexuales y humanos, lo que permite la gente a descubrir sus propios deseos y las singularidades y los lleva a la emancipación social.
\end{abstract}

Palabras clave: Genero, Família, Psicologia Clinica, Psicologia Social.

\section{Introdução}

Neste relato, pretendemos problematizar as intersecções entre relações familiares, gênero e emancipação psicossocial a partir da prática de estágio curricular "Clínica Transdisciplinar: gênero, saúde e família”, vinculado à formação do(a) psicólogo(a) junto ao Departamento de Psicologia Clínica da Universidade Estadual Paulista "Júlio de Mesquita Filho" (Unesp) campus de Assis, do curso de Psicologia, e da revisão bibliográfica, com referencial esquizoanalítico e nos estudos de sexualidade e gênero. Nesse sentido, nos apropriamos da ideia de família como um produto de formas históricas e culturais de organização entre as pessoas, que não consiste somente em referências biológicas, naturais e religiosas. Assim, podemos entender que a formação da família vem se modificando em diferentes contextos sócio-históricos e culturais, dando visibilidade para diversas representações sociais do que seja a família.

No entanto, a ideia de família que prevalece em grande parte de nossa sociedade diz respeito ao modelo heteronormativo procriativo e religioso, um modelo normativo ideal que produz indivíduos úteis e dóceis, o que não significa que abarque todas as diversas formas de organizações familiares atuais, nem mesmo as mais predominantes (Uziel, 2004; Zambrano, 2011). Como nos sugere Vivas (2005, p.112):

Es en la família donde se aprenden primeiramente valorestalescomolatolerância,lanodiscriminación, la justicia, la solidariedad, y sus correspondientes antivalores la agresividad, la exclusión, la injusticia, el egoísmo, junto con la violência y el maltrato. También se incorporan visiones en relación con la equidad o inequidad de género, a través de lós roles femeninos y masculinos de progenitores y otros miembros del hogar.

Entre as linhas que tecem as configurações familiares, podemos evidenciar uma tecelagem complexa que abarca diversos dispositivos e estratégias que dão manutenção ao jogo parental, que reifica e fortalece as relações entre pais, filha(o)s e agregada(o)s, no sentido de promover normas que dão manutenção a valores e sentidos expressos por discursos na maioria das vezes ascéticos e higienistas, mas também de resistências a esses mesmos modelos que duelam entre o conservadorismo e a flexibilização reivindicada por novos arranjos e relações familiares.

Uma linha, em meio a tantas outras linhas, que é muito forte e determinista encontrada nessa tecelagem diz respeito à linha dos gêneros que educa e disciplina os corpos e seus prazeres desde a infância e se prolonga por toda vida. Como tentativa de conceituar gênero, nos apoiamos em Scott (1995, p.24) que afirma:

Minha definição de gênero tem duas partes e diversossubconjuntosqueestão inter-relacionados, mas devem ser analiticamente diferenciados. O núcleo da definição repousa numa conexão in- 
tegral entre duas proposições: (l) o gênero é um elemento constitutivo de relações sociais baseadas nas diferenças percebidas entre os sexos, e (2) o gênero é uma forma primária de dar significado às relações de poder.

Isto, por sua vez, atesta que os gêneros são categorias que participam ativamente dos processos de subjetivação e por isso pode ser reconhecido como uma forma primária de produção de sujeitos. Desta forma, apropriamo-nos dos apontamentos feitos por Netting, Wilk e Arnould (1984), citados por Scott (2005), que define o conceito de família como:

Família remete à incorporação de relações de consanguinidade e aliança em torno da normatização de identificação de pares com relações sexuais estabelecidas, que empregam noções hierarquizadas de gênero, de geração e de idade para construir referências de pertencimento social a grupos. Desta forma, quem faz parte da família produz, reproduz, distribui, herda e reside (p.79).

De modo bastante ampliado, Scott (2005) afirma que o termo família pode remeter tanto a um grupo, uma linha ou rede de parentes, e mesmo a uma noção de solidariedade. De modo concomitante, a ideia de um sistema disciplinar e regulador de sexo/gênero/ desejo/práticas sexuais, apresentados por Butler (2003), indica que se uma pessoa nasce com o sexo de macho será exclusivamente masculino, seu desejo heterossexual e sua prática sexual ativa; se nascer com sexo de fêmea, seu gênero será feminino, seu desejo heterossexual e sua prática sexual passiva, de modo que se algo for alterado dessa lógica, não será reconhecido como sujeito de direito ou, caso seja considerado, será visto como uma abjeção, o que possibilita a manutenção da efetivação de práticas heteronormativas e falocêntricas que restringem a família a um modelo reducionista, produzindo a invisibilidade de qualquer outra configuração familiar que escape às suas premissas. Logo, isso contribui com as ações do biopoder que disciplinam os corpos e as biopolíticas reguladoras das relações interpessoais e familiares, e indicam o modelo único de família dentro de racionalidades binárias e universalistas que engessam as possibilidades de criação e composição de outros cenários familiares. Essas ações foram se constituindo através de diversas transformações ocorridas na vida familiar, que convivia simultaneamente nos espaços público e privado até a Idade Média, para se tornar predominantemente privada e intimista a partir do século XVIII, na qual favoreceu tanto o exercício da proteção social como da regulação da vida familiar.

Até o século XIX, nos esclarece Foucault (1988), havia uma flexibilidade maior nas relações familiares, assuntos que hoje são tratados como proibidos ou restritos às esferas da intimidade, como as sexualidades e seus prazeres, eram tratados publicamente em festas através de relatos, em alto e bom tom, por pessoas que contavam suas intimidades. Somente após essa época, tais assuntos, deixaram de serem pautas da sala de casa e passaram a ser restrito ao quarto conjugal, antes, aponta Foucault (1988): os corpos pavoneavam.

Das proibições inicialmente produzidas no território íntimo e doméstico, vemos o contágio proibitivo nas outras esferas da vida que determinam os lugares dos discursos que passam a serem divididos em públicos e privados. Desta forma, estes sujeitos eram (e ainda são) atravessados por ordens normativas que definem os lugares, discursos, prazeres e posições políticas que os mesmos devem assumir, para que as ordens dadas pelo biopoder e os processos de captura e regulação biopolítica sejam mantidas (Foucault, 1988; 2008).

Vale ressaltar que os conceitos de biopoder e biopolítica surgiram com Foucault (1988), na sua obra "História da Sexualidade I: a vontade de saber". Os termos são utilizados para nomear os poderes inicialmente relacionados às ações do estado, os quais passam a estar presentes depois, nas demais relações humanas exercidas sobre a vida e seus viventes. Assim como aponta Duarte (2008), o que se produz por meio da atuação específica do biopoder e da biopolítica não é só o indivíduo dócil e útil, mas a própria gestão da vida, do corpo social, ou seja, a regulação dos componentes da sociedade.

Nesse sentido, cria-se um modelo hegemônico de família: o da família conjugal burguesa, que passa a ideia ilusória de maiores garantias de felicidade. No entanto, esta vem se tornando obsoleta em sua configuração, sendo demarcada cada vez mais por um viés desestabilizador que a coloca oscilante frente ao modelo único estabelecido, denunciando seu caráter processual, pois as transformações históricas da família têm mostrado a convivência de mais de um modelo familiar (Uziel, 2004; Zambrano, 2011). Da 
mesma forma, José Ignácio Galán (2009), em referência ao território espanhol que se aproxima da realidade brasileira, nos traz a ideia de uma mudança nas configurações familiares, devido aos:

Divorcios, separaciones, nuevos casamientos, padres y madres solteras, parejas sin hijos, hijos e hijas al margen del matrimonio, parejas sin vínculo formal, famílias homosexuales, varias geraciones conviviendo em la misma casa, abuelas criando a nietos, mujeres fuera del hogar, familiar recompuestas, personas que vivien solas, que comparten residência com otras sin vínculos de filiación o alianza, migraciones y familias transnacionales, adopciones internacionales y tantas otras realidades hacen pensar que la visión de la família nuclear heterosexual como medula básica de las relaciones de parentesco está en crisis en nuestro contexto cultural (p.51).

Partindo dessa ideia, notamos o surgimento de diferentes configurações familiares, entre elas as monoparentais, as recompostas (aquelas, nas quais, um dos cônjuges [ou ambos] teve união anterior com filho[a]s), as homoparentais, entre outras possibilidades (Zambrano, 2011). Sendo assim, são diversas as linhas que tecem as configurações familiares, dentre elas se situam as linhas das relações de gênero que educam e disciplinam os corpos e seus prazeres desde a infância e se prolongam por toda vida. Como tentativa de conceituar gênero, nos apoiamos em Scott (1995), que afirma:

Minha definição de gênero tem duas partes e diversossubconjuntos que estãointer-relacionados, mas devem ser analiticamente diferenciados. O núcleo da definição repousa numa conexão integral entre duas proposições: (l) o gênero é um elemento constitutivo de relações sociais baseadas nas diferenças percebidas entre os sexos, e (2) o gênero é uma forma primária de dar significado às relações de poder (p.24).

Isto, por sua vez, atesta que gênero é uma categoria que participa ativamente dos processos de subjetivação - Deleuze e Guattari (1995) problematizam que existe produção da subjetividade, assim como se produz mercadorias (exemplo, o leite condensado), existe o processo de produção da subjetividade, que é extrapessoal e infrapsíquico, mas este processo ocorre sempre no registro social, ou seja, somos atravessados por diversas linhas que vão nos moldando ao longo de nossas vidas - e, por isso, esse processo pode ser reconhecido como uma forma primária de produção de sujeitos. A importância das relações entre sexos dentro da família é clara, uma vez que se concretizou centrada no homem, sendo as mulheres consideradas meras coadjuvantes. O patriarca - o patriarcado não designa o poder do pai, mas o poder dos homens, ou do masculino, enquanto categoria social - tinha sob seu poder a mulher, as crianças, as pessoas escravizadas e os vassalos (Xavier, 1998).

No Brasil, o modelo familiar também teve como ponto de partida o modelo patriarcal, que ainda prevalece na vida e na esfera política brasileira (Chauí, 1989). Dessa forma, Jacques Donzelot (2001) aponta que passou a existir um abismo, desde o século XVIII, quanto à educação de meninos e meninas dentro das famílias. No primeiro caso, se estimulava e encorajava as experiências pré-conjugais, já no segundo, prevalecia um discurso de preservação e controle dos corpos.

Assim, as famílias se tornavam mais tradicionais (e bem-vistas) à medida que suas filhas eram mais preservadas do que as de outras famílias. Neste viés, a figura da menina/mulher volta-se para o estereótipo de dona do lar, cuidadora dos membros e guardiã da moral da família (Costa, 2004). Portanto, desse ponto de vista, as mulheres não tinham nenhum valor, legitimava-se o controle da sexualidade reprodutiva e de seus corpos pelos homens, fazendo com que o masculino obtivesse vantagens e controle dos papéis sexuais e sociais (Scott, 1995).

As distinções biológicas entre os corpos de homens e mulheres só começaram a ser pensadas no final do século XVIII, mas a hierarquia na forma de representação da mulher com relação ao homem predominou por muito tempo e teve grande influência nos papéis de gênero desempenhados por cada um, em suas ações políticas, econômicas e culturais, o que podemos ainda constatar na atualidade. Em suma, Laqueur (2001) afirma que ser homem ou mulher significava, e ainda significa, ocupar uma posição específica na sociedade, assumir um papel dentro de uma referida cultura, consolidar políticas dos prazeres. Ainda hoje, no campo de nossas intervenções psicossociais, encontramos capturas e proibições machistas que roubam das mulheres a liberdade de escolhas 
profissionais e de participação social nas tomadas de decisões da sociedade, ou seja, as mantém fora do acesso à cidadania.

Assim, comprovando que, apesar das mulheres terem conquistado muitos direitos, por volta de meados do século XX, a equidade ${ }^{1}$ para as mulheres ainda é ficção, pois os processos de subjetivação feminina contemporâneos, conforme observados em nosso campo de atendimentos psicossociais, ainda se mantêm atrelados às premissas conservadoras orientadas por machismos e misoginias, associados à heteronormatividade (entendemos a heteronormatividade a partir da heterossexualidade compulsória que agencia as práticas e relações afetivas) e ao falocentrismo, os quais não permitem às próprias mulheres se autorizarem a exercer seus direitos, a terem direitos, e a conquistar novas posições sociais, políticas e culturais que as emancipem (Narvaz, \& Koller, 2006; Strey, 2000). Outrossim, além do atravessamento de gênero, é importante frisar que as mulheres sujeitas deste estudo são subjetivadas por outros marcadores sociais de estigmas, tais como sexo, raça/cor e etnias. Segundo Vivas (2005), esta situação continua acontecendo devido:

Los estereotipos de género en el seno de la família favorecen la inequidad hacia las mujeres, tanto en lo que refiere a la desigual carga de tareas en el âmbito doméstico como hacia el manejo del poder, incluyendo el ejercicio de distintos tipos de violência" (p. 112).

Alguns estudos com famílias brasileiras (Narvaz, \& Koller, 2006; Salem, 2004) demonstram existir, ainda, estigmas acerca da divisão do trabalho dentro do ambiente doméstico, de acordo com a construção social das relações de gênero: a mãe deve cuidar da prole e o pai deve prover o sustento, ensinar a disciplina e ter toda a autoridade. Desta forma, temos mulheres com sobrecargas físicas e psíquicas, o que leva muitas vezes ao adoecimento: estresse, depressão, angústia e dependência em psicofármacos. Esta produção de sofrimento psicossocial, apontada por
Vivas (2005), também pode ser observada nas vivências relatadas nos atendimentos psicossociais, que atestam o uso de psicofármacos como falso alívio de suas tensões, pois estas marcas e sofrimentos não são só bioquímicos, são principalmente existenciais.

Com isso, podemos comprovar que, mesmo com as transformações na configuração da família, os modelos normativos de "recomendados" pela sociedade atual, ainda não correspondem à realidade das configurações existentes na sociedade contemporânea e suas demandas em contextos sócio-históricos previamente definidos.

Neste sentido, as configurações ou composições familiares foram e continuam sendo traçadas sob múltiplos impulsos e fluxos que interferem na sua conformação, formando o que Deleuze e Guattari (1995) chamaram de rizoma, termo que é "emprestado" por esses autores da botânica, e a partir do qual, é definida a ideia de feixes de linhas que compõem verdadeiras redes sem um eixo principal. De modo complementar, ao falar do rizoma, esses autores, nos informam que:

Não é feito de unidades, mas de dimensões, ou antes de direções movediças. Ele não tem começo nem fim, mas sempre um meio pelo qual ele cresce e transborda. Ele constitui multiplicidades lineares a n dimensões, sem sujeito nem objeto... Oposto a uma estrutura..., o rizoma é feito somente de linhas... O rizoma é uma anti genealogia. É uma memória curta ou uma anti memória. O rizoma procede por variação, expansão, conquista, captura, picada..., o rizoma se refere a um mapa que deve ser produzido, construído, sempre desmontável, conectável, reversível, modificável, com múltiplas entradas e saídas, com suas linhas de fuga... unicamente definido por uma circulação de estados... todo tipo de "devires" (Deleuze, \& Guattari, 1995, p. 32).

Assim, ao invés de pensarmos em famílias com contornos limitados e fechados em si, como é a família nuclear burguesa heteronormativa, religiosa e

\footnotetext{
${ }^{1}$ Entende-se por equidade de gênero a igualdade de tratamentos entre homens e mulheres no mercado de trabalho, incluindo mesmas condições salariais e de trabalho. Atualmente, as desvantagens das mulheres em relação aos homens no mercado de trabalho têm sido um dos temas que envolvem a responsabilidade social nas empresas, principalmente porque as mulheres são provedoras de uma família e hoje assumem um papel econômico muito significativo no contexto social global. Recuperado em: 30 de maio de 2014, de http://www. ecodesenvolvimento.org/colunas/vivian-blaso/equidade-de-genero-e-a-responsabilidade-social\#ixzz33DkTSjgx
} 
reprodutiva, entendemos que ao considerar a ideia de cruzamentos de múltiplos componentes de subjetivação que se ligam, desligam e religam, influenciando a construção da subjetividade dos sujeitos, não haverá um modelo único de família, mas, para usar a expressão cunhada por Galán (2009), poderíamos falar em "famílias diversas".

\section{Problematizando o território geopolítico e existencial: processos de emancipação}

Após revisão bibliográfica e problematizações sobre famílias, sexualidade, gênero e emancipação psicossocial, consideraremos estas linhas a partir das intervenções realizadas pelo estágio citado no início do relato. Foram realizados atendimentos psicossociais clínicos em um bairro periférico, de uma cidade de pequeno porte, que era atravessado por diversos problemas de ordem social, econômica, política e cultural. Ao longo de três anos, pudemos cartografar neste território um cenário composto por prostituição, tráfico e uso de drogas ilícitas, desemprego, trabalhadores com baixa remuneração, violências (sociais, sexuais e de gênero), falta de lugares para o lazer da população, ou seja, ausência de políticas públicas inclusivas e viáveis que visassem o bem-estar biopsicossocial da comunidade.

Vale colocar que a cartografia é um procedimento metodológico da Geografia para representar os contornos de um dado território através de mapas ou cartas, por meio do que viu e sentiu o(a) cartógrafo(a). Dentro da Psicologia, é um método utilizado por Deleuze e Guattari (1995), que possibilita a leitura das relações estabelecidas pelos processos desejantes no campo social e o mapeamento de linhas subjetivas influenciadas pelos saberes, poderes e prazeres presentes nos discursos e figurações que nos atravessam ao longo da vida. Há que se ter cuidado com o uso da expressão "bem-estar", pois corre-se o risco de afirmar um viés adaptativo da Psicologia, o qual criticamos neste artigo, de modo que, somente poderemos considerar o "bem-estar" a partir do autorreferencial das pessoas atendidas e o modo pelo qual cada uma delas concebe seu "bem-estar".

A ideia de problematizar a respeito das intersecções entre relações familiares, de gênero e emancipação psicossocial, com destaque para as mulheres, surgiu através dos atendimentos realizados durante o estágio no bairro. O estágio tinha como base teórica os estudos de gênero, a teoria esquizoanalítica (Deleuze; \& Guattari, 1995), considerando que a esquizoanálise cartografa os processos desejantes no campo social, que incendem-se sobre pessoas, grupos ou instituições e as teorias de Michel Foucault, que nos beneficiam com as problematizações sobre as relações de poder. Para isso, havia atendimentos de diversas ordens: pronto atendimento, oficinas terapêuticas, atendimento em grupo, acompanhamento terapêutico e atendimento domiciliar.

As histórias de vidas apontadas neste relato são baseadas nos atendimentos realizados em uma das salas da Unidade Saúde da Família, localizada no bairro e/ou em visitas domiciliares a essas pessoas, durante os anos de 2010 e 2012. Os encontros eram realizados uma ou duas vezes por semana, conforme a necessidade, e tinham a duração de 60 a 90 minutos. Para ilustrar um pouco das questões que envolvem essas discussões, trouxemos o relato de dois atendimentos que aconteceram durante esse período.

Em um dos atendimentos, realizado inicialmente de forma individual e, em um segundo momento, grupal, uma mulher de 46 anos, que expressava experiências de violências, também vividas por outras mulheres do território em questão, relatava que trabalhava do período da manhã até a tarde e se orgulhava por sempre fazer todos os serviços domésticos sozinha, mas que, quando ficou "doente" (diagnosticada pelo psiquiatra com depressão e transtorno de ansiedade), não conseguia mais fazer as mesmas atividades, 0 que se tornara um disparador de impotência e culpabilização por não cumprir aqueles deveres ditos de mulher. Vale ressaltar que nossa intenção de tomar a queixa de uma mulher, nos remete aqui à ideia de sujeito coletivo, ou seja, sua queixa de violência física, moral e psicológica diz respeito às queixas de muitas mulheres que se encontram em igual situação de violência, pelas quais são expostas cotidianamente.

Após alguns meses, ela relata que estava melhor e, como medidor de sua melhora, disse que já conseguia fazer os serviços domésticos e que, portanto, estava cumprindo suas obrigações. Por meio desse tipo de opressão, podemos ver como o machismo, a misoginia e a normatividade, das quais vimos falando, ainda habitam o imaginário das pessoas e interferem fortemente na construção dos estereótipos sociais. No entanto, no decorrer dos atendimentos, conseguimos cartografar algumas linhas de fuga - de acordo com Kamkhagi (2005, p. 123), "las líneas de fuga, son 
las líneas de ruptura, aquellas que rompen ló que era, rompem la existencia y buscan outro camino, outro Sendero. La figura que corresponde a la línea de fuga sería el clandestino." -, quando essa mulher relata que pediu ao marido para contratar uma pessoa para passar as roupas da família, pois naquele momento se dedicava a outras atividades. É importante esclarecer, nesse sentido, a complexidade das tomadas de decisões, tendo em vista suas consequências sejam para os outros, ou para si mesma. Para que adotasse essa decisão, muitos de seus valores foram revistos, o que implicou em uma série de enfrentamentos que podem ter causado ansiedade, angústia, insegurança e um sentimento de impotência, nada fáceis de se superar, considerando-se os processos de subjetivação submissão, chamada por Foucault (2010) de "assujeitamento", pelos quais passou ao longo de sua vida e que estão associados às formas de submissão em relação às ordem normativas falocêntricas e heterocentradas.

Podemos inferir que, a partir da relação terapêutica e dos discursos emitidos nos encontros, houve mudanças de autorreferenciais provocadas por esse modo de atendimento terapêutico que favorece a problematização e fuga das armadilhas normativas, fazendo com que o sujeito se distancie, ainda que de modo sutil, dos modelos previamente dados, nesse caso, de como ser mulher: passiva, submissa, casada, mãe e dona do lar; priorizando assim, finalmente, o seu bem-estar biopsicossocial e político. Aqui vale colocar que, para os atendimentos, nos baseávamos em teorias e estudos da Psicologia que se preocupam em não patologizar e reduzir a vida a etapas de desenvolvimento, o que equivaleria dizer que nossos encontros visavam problematizar esses sujeitos procurando evidenciar que os eles podem e devem ser potencialmente singulares.

Em outro atendimento individual, uma mulher de 40 anos começou relatando que tinha diversas discussões e brigas físicas com o marido. Após alguns meses em atendimento, assim negociando e renegociando os seus processos de subjetivação, e problematizando as relações de submissão e passividade diante da autoridade marital, ela propõe ao seu marido dormirem primeiramente em um quarto separado, depois morarem em casas diferentes, desde que o mesmo continuasse a ajudar nas despesas econômicas da casa e das crianças.

Diante da situação, observamos o crescimento na potência de vida dessa mulher, que conseguiu vencer partes das capturas normativas que faziam manter o marido junto à família, ainda que para isso tivesse que lhe ser submissa, comprometendo a sua individualidade. Tomadas as resoluções, mesmo mantendo o homem como o provedor da família, agora ela já pode ter a autonomia de desejos próprios e fazer planos de futuro que a coloquem mais próxima de sua emancipação psicossocial, política e cultural, ou seja, a mantém um pouco mais distante das amarras do sexo, gênero, desejo e práticas sexuais, que assessoram o biopoder e as imposições da heteronormatividade como obrigatória.

Muitas mulheres do bairro em que atuávamos ainda não conseguiram repensar as posições normativas ditadas pelas relações de gênero, nas quais o homem trabalha e sustenta a casa, enquanto a mulher cuida das crianças e da manutenção da família nuclear procriadora. Com isso, não investem em suas vidas profissionais, em seus desejos, em sua emancipação devido ao fato de não se sentirem autorizadas dentro do modelo falocêntrico e restrito do patriarcado, ainda presente no território que se inserem, caracterizando o que podemos chamar de despotencialização de suas vidas. Dentro desse cenário, há ainda aquelas que sofrem diversos tipos de violências, sejam elas de ordem doméstica, sexual, racial, geracional e/ou de gênero, em níveis emocionais, físicos e morais - ou todos juntos - o que vem a fortalecer ainda mais a submissão com relação ao homem, contribuindo para uma baixa autoestima, e consequentemente para a perda da crença em si mesma, entre outros problemas.

Através do acesso a trabalhos que abordam essa questão, pudemos perceber que o cenário que encontramos no bairro não foge à realidade de outros territórios brasileiros, conforme podemos constatar pelas pesquisas coordenadas por Maluf e Tornquist (2010), compiladas e publicadas no livro "Gênero, Saúde e Aflição: abordagens antropológicas”. Nesse território, existem também cenários de lutas de gênero intrafamiliares, as quais, em sua maioria, são ainda de ordem patriarcal. No entanto, conseguimos notar linhas de fuga, nas quais as mulheres que têm acesso a bens e serviços de qualidade, informações sobre direitos sexuais e humanos, ações de empoderamento social e político, assim como disponibilidade e desejo de mudança, conseguem ampliar seus universos de referências existenciais, dessa forma, adquirem maior 
autonomia sobre suas vidas e, algumas vezes, o poder na família.

A configuração da igualdade de direitos no campo da sexualidade e do gênero ainda se encontra bastante precária, mas configuram-se como uma novidade no campo de problematização sobre os direitos humanos e em especial os direitos emancipatórios das mulheres. De acordo com Petchesky (1999), os direitos sexuais surgem no dicionário dos direitos humanos para que sejam reconhecidas as diversas orientações sexuais e suas necessidades de expressão. No entanto, por incrível que possa parecer, em pleno século XXI, os direitos sexuais ainda se encontram fora do rol dos direitos humanos, o que denuncia a ausência de políticas sexuais que respeitem e reconheçam a diversidade humana que se efetiva no campo das expressões da sexualidade e das relações de gênero, mantendo assim, as escalas hierárquicas de desigualdades de direitos entre homens e mulheres. Aqui, fica patente a assertiva feita por Deleuze (1990), quando afirma que:

Acreditar no mundo é o que mais nos falta; perdemos o mundo, ele nos foi tomado. Acreditar no mundo é também suscitar acontecimentos, mesmo que pequenos, que escapem do controle, ou então fazer novos espaços-tempos, mesmo de superfície e volume reduzidos... É no nível de cada tentativa que são julgadas a capacidade de resistência ou, ao contrário, a submissão a um controle. São necessários, ao mesmo tempo, criação e povo (p. 3).

Em contrapartida, outras mulheres do mesmo bairro já conseguem ampliar seus universos de referências existenciais, passando a questionar as ordens, os valores e os discursos impositivos, produzindo em decorrência novos lugares e práticas possíveis. Assim, as violações dos direitos sexuais e humanos podem ser evidenciadas nas relações contemporâneas visto que estão sensivelmente presentes nos relatos de atendimento psicossociais realizados na Estratégia Saúde da Família.

\section{Considerações finais}

A partir da revisão bibliográfica e de nossas experiências adquiridas no bairro em questão, através de atendimentos individuais proporcionados pelo está- gio curricular da grade de ensino em Psicologia da Unesp - campus de Assis, em nossa cartografia concluímos que é de extrema importância problematizar as linhas que atravessaram e atravessam as relações familiares das mulheres e suas interfaces com as questões de gênero e possibilidades emancipatórias. Entendemos que, quando falamos destas mulheres, estamos, também, falando de uma multiplicidade de mulheres em diversos territórios.

A categoria de análise aqui proposta, a respeito de famílias, mostra que tanto nas teorias elencadas quanto nos relatos das mulheres atendidas o conceito de família se mostra ainda aprisionado às estruturas patriarcais, falocêntricas e heteronormativas e se reduzem ao modelo tradicional da família burguesa, nuclear e reprodutiva.

Desta forma, em uma perspectiva crítica, cartografamos a emergência da problematização dos novos arranjos familiares, tais como os das famílias monoparentais, homoparentais e com ausência das figuras do pai e da mãe, entre outras possibilidades. Há que se considerar, ainda, as novas demandas que surgem nos tempos atuais e solicitam novas posições conceituais e políticas que incluem e moldam as ações dessas novas atrizes e atores no cenário familiar. Neste sentido, a própria Psicologia (assim como outras áreas do saber - enfermagem, medicina, serviço social etc.) precisam rever as suas práticas e conceitos, considerando suas tendências, muitas vezes reducionistas, que pouco contribuem para as problematizações trazidas pelos(as) componentes das famílias que ganham cada vez mais visibilidade e importância na configuração da atualidade, desmistificando assim a ideia de uma única possibilidade de composição familiar, representada por um casal heterossexual e sua prole.

Da mesma forma, a categoria de análise "gênero", quando pensada dentro do escopo de atuação da Psicologia, muitas vezes se mantém invisível, fazendo com que sua dimensão subjetivadora não seja contemplada como elemento de constituição dos sujeitos, o que gera uma prática muitas vezes reducionista e com o olhar focado somente no indivíduo (aquele que não se divide, que está totalizado) e nas patologizações que lhe impostas ao longo da vida.

As relações de gênero, como apresentadas nos textos citados, se mostram como uma linha de subjetivação primária das expressões sexuais e seus prazeres, que, por sua vez, solicita a ampliação de referên- 
cias quando em interfaces com outras categorias de análise, como classe social, raça/cor, geração, orientação sexual e estilos de vida, que podem ajudar a Psicologia a problematizar as relações humanas contemporâneas, as quais são diversas e se mantêm em construção permanente.

A dimensão das relações de gênero abre precedentes para que as violências, presentes não apenas no universo familiar, que ainda se mantém carregado de machismos, misoginias, racismos e homofobias, possam ser analisadas sob outras perspectivas que rompam com estas imposições normativas, e que permitam à Psicologia produzir práticas emancipatórias e políticas que respeitem a existência e emergência da diversidade, de modo a não produzir uma classificação reducionista das relações humanas contemporâneas, que esteja presa a modelos de conduta cristalizados.

As interfaces possíveis entre família e gênero abrem novas problematizações a respeito das expressões humanas na contemporaneidade e requerem uma revisão urgente de postulados teóricos e metodológicos da Psicologia que foram produzidos em outros contextos sócio-históricos e tentavam responder às demandas próprias daquele tempo, considerando a dinâmica da vida, que não se cansa de processar possibilidades, para que devires outros possam ganhar visibilidade.

Essas mesmas interfaces abrem precedentes para problematizações a respeito dos processos emancipatórios que permitam às pessoas, em especial às mulheres, ter acesso a bens e serviços de qualidade e respeito a suas demandas desejantes, caracterizando assim aquilo que Guattari e Rolnik (2005) - na obra "Micropolítica: cartografias do desejo" - chamaram de direito fundamental à singularidade; isto, por sua vez, nos remete à dimensão do exercício pleno, amplo e democrático da cidadania que, para além dos direitos reprodutivos, considerem também os direitos sexuais.

Com isso, a dimensão psicossocial surge como uma ideia ampliada que vai além da noção de sofrimento psíquico, contemplada aqui pelas políticas relacionais inclusivas, na qual o sofrimento vivido em consequência das amarras de sexo, gênero, desejo e práticas sexuais (Butler, 2003) favorece os olhares dos(as) operadores(as) da Psicologia na ampliação da compreensão do sofrimento como psicossocial, pois, com uma população maciçamente pobre, majorita- riamente negra, muitas vezes excluída e relegada à própria sorte e solitária, dentre outros possíveis atributos, nosso país apresenta faces de sofrimento psicossociais que são recorrentes no cotidiano das pessoas e chegam a intervir, ainda, em seus direitos de ser, estar, ir e vir.

Através dos mapeamentos realizados nos atendimentos às mulheres, apontados neste trabalho, podemos perceber que muitas delas ainda estão presas às linhas duras que engessam as identidades, aos modelos reducionistas de base patriarcal e heteronormativa, as quais as despotencializam e as colocam como pessoas sem direitos, fechadas em seus papéis sociais historicamente construídos (donas do lar, cuidadoras da família, inferiores aos homens e destituídas de desejos próprios).

No entanto, através dos atendimentos psicossociais e políticos realizados pelos(as) estagiários(as) de Psicologia, essas mulheres têm potencializado suas individualidades e conseguido criar linhas de fugas, nas quais podem ser reivindicados direitos de equivalência perante os homens (sejam maridos, filhos ou chefes), e, com isso, têm conseguido ganhar espaço dentro do ambiente familiar, deixando de ser submissas, simples objetos reprodutivos e ascendem ao espaço público, atuando onde, até então, somente os homens brancos de classe média tinham a ampla legitimidade em atuar, gerenciando assim novas formas e novos processos de subjetivação.

Dessa forma, acreditamos que a Psicologia, com um olhar ampliado e crítico, pode ajudar na potencialização da vida dessas mulheres, e na construção de novos paradigmas desvencilhados daquelas formas estereotipadas, às quais foram submetidas. Contudo, os(as) psicólogos(as) devem estar empenhados(as) na revisão de seus próprios valores e conceitos e atuar como problematizadores(as) perante o relato dessas vivências, dentro dos direitos e desejos de cada um(a), evitando, assim, atuar de acordo com uma Psicologia restrita a diagnósticos reducionistas de tratamentos e curas, e contribuindo para afirmar o lugar da mulher não mais como submissa ao homem nos diversos campos da escala social, como demonstram as experiências relatadas pelas mulheres atendidas em nosso núcleo atendimento psicossocial, e sim, ao lado, como detentora dos mesmos direitos.

Com isso, acreditamos estar contribuindo para que as mulheres rompam e ressignifiquem discursos de ordem falocêntrica, que as restringem a um uni- 
verso limitado no exercício de suas vidas. Assim, uma Psicologia implicada politicamente com a vida e a realidade das mulheres (não somente das mulheres, mas, com as de todos os sujeitos) pode se tornar um dos

\section{Referências}

Butler, J. (2003). Problema de gênero: feminismo e subversão da identidade (3a ed.). Rio de Janeiro, RJ: Civilização Brasileira.

Costa, J. F. (2004). Ordem médica e norma familiar (3a ed.). Rio de Janeiro, RJ: Graal.

Chauí, M. (1989). Conformismo e resistência: aspectos da cultura popular no Brasil (2a ed.). São Paulo, SP: Brasiliense.

Deleuze, G. (1990). O devir revolucionário e as criações políticas: entrevista de Gilles Deleuze a Toni Negri. Novos Estudos, (28), 67-73. Recuperado de http://novosestudos.uol.com.br/vl/files/uploads / contents/62/20080624_o_devir_revolucionario.pdf

Deleuze, G., \& Guatarri, F. (1995). Mil platôs: capitalismo e esquizofrenia, Vol. 1 (Coleção Trans). Rio de Janeiro, RJ: Editora 34.

Duarte, A (2008). Sobre a bio-política: de Foucault ao século XXI. Cinética, 1, 1-16. Recuperado de http:// www.revistacinetica.com.br/cep/editorial.html

Foucault, M. (1988). História da sexualidade I: a vontade de saber. Rio de Janeiro, RJ: Graal.

Foucault, M. (2008). Segurança, território, população: curso dado no Collège de France (1977-1978). São Paulo, SP: Martins Fontes.

Foucault, M. (2010). Repensar a política: ditos e escritos VI. Rio de Janeiro, RJ: Forense Univesitária.

Galán, J. I. P. (2009). Entender la diversidad familiar: relaciones homosexuales y nuevos modelos de familia. Barcelona: Bellaterra.

Guattari, F., \& Rolnik, S. (2005). Micropolíticas: cartografias do desejo. Petrópolis, RJ: Vozes.

Kamkhagi, R. V. (2005). El esquizoanálisis y sus líneas. In A. M. Del Cueto. Diagramas de psicodrama y grupos: cuadernos de bitácora (pp. 121-134). Buenos Aires: Asociación Madras de Plaza de Mayo.

Laqueur, T. (2001). Inventando o sexo. Rio de Janeiro, RJ: Relume Dumará.

Maluf, S. W., \& Tornquist, C. S. (Orgs.). (2010). Gênero, saúde e aflição: abordagens antropológicas. Florianópolis, SC: Letras Contemporâneas. dispositivos de enfrentamento mais eficazes contra as formas de machismos e misoginias que as impedem de alcançar a emancipação psicossocial e política de forma efetiva.

Narvaz M. G., \& Koller, S. H. (2006). Famílias e patriarcado: da prescrição normativa à subversão criativa. Psicologia e Sociedade, 18(1), 49-55. doi:10.1590/S0102-71822006000100007

Petchesky, R. P. (1999). Direitos sexuais: um novo conceito na prática política internacional. In R. M. Barbosa, \& R. Parker (Orgs.), Sexualidade pelo avesso: direitos, identidades e poder (pp. 15-38). São Paulo, SP: 34.

Scott, J. (1995). Gênero: uma categoria útil de análise histórica. Educação \& Realidade, 20(2), 71-99.

Scott, P. (2005). Gênero, família e comunidades: observações e aportes teóricos sobre o Programa Saúde da Família. In S. Monteiro, \&W.Vilela (Orgs.), Gênero e saúde: Programa Saúde da Família em questão (pp. 75-100). São Paulo, SP: Abrasco.

Uziel, A. P. (2004). Homossexualidade e parentalidade: ecos de uma conjugação. In: HEILBORN, M. L. (Org.). Família e Sexualidade (pp. 87-117). Rio de Janeiro: Editora FGV.

Vivas, P. (2005). La familia como foco: cuestiones em juego, problematizaciones de género. In S. Monteiro, \& W. Vilela (Orgs.), Gênero e saúde: Programa Saúde da Família em questão (pp.113-120). São Paulo, SP: Abrasco.

Xavier, E. (1988). Declínio do patriarcado: a família no imaginário feminino. Rio de Janeiro, RJ: Record.

Zambrano, E. (2011). Mesa: Psicologia, sexualidade, novas configurações familiares e aspectos legais da promoção de direitos. In Conselho Federal de Psicologia, Psicologia e diversidade sexual: desafios para uma sociedade de direitos (pp.109-116). Brasília, DF: o autor.

André Masao Peres Tokuda

Mestre em Psicologia pela Universidade Estadual Paulista "Júlio de Mesquita Filho" (UNESP) - Campus de Assis; Coordenador e docente do curso de Psicologia das Faculdades Integradas de Três Lagoas/MS (AEMS). Membro do Grupo de Estudos e Pesquisas sobre as Sexualidades - GEPS

E-mail: andremasao@hotmail.com 


\section{Wiliam Siqueira Peres}

Doutor em Saúde Coletiva pela Universidade Estadual Paulista "Júlio de Mesquita Filho" - Unesp, Assis - SP. Pós-doutorado em Psicologia e Estudos de Gênero pela Universidade de Buenos Aires, Buenos Aires, Argentina. Professor de graduação e pós-graduação (mestrado e doutorado) em Psicologia da Universidade Estadual Paulista "Júlio de Mesquita Filho", Assis - SP. Brasil.

E-mail: pereswiliam@gmail.com

\section{Caio Andrêo}

Mestre em Psicologia pela Universidade Estadual Paulista "Júlio de Mesquita Filho" (UNESP) - Campus de Assis; Docente de graduação em Psicologia das Faculdades Integradas de Ourinhos (FIO) e Faculdade da Alta Paulista (FAP). Membro do Grupo de Estudos e Pesquisas sobre as Sexualidades - GEPS

E-mail: caioandreo@gmail.com
Endereço para envio de correspondência: Universidade Estadual Paulista "Júlio de Mesquita Filho” - Unesp. Avenida Dom Antônio, Parque Universitário.

Assis - SP. Brasil.

Recebido 14/07/2014

Aprovado 11/11/2016

Received 07/14/2014

Approved 11/11/2016

Recibido 14/07/2014

Aceptado 11/11/2016

Como citar: Tokuda A. M. P., Peres, W. S., \& Andrêo, C. (2016). Família, gênero e emancipação psicossocial. Psicologia: Ciência e Profissão, 36(4): 921-931. doi: 10.1590/1982-3703001022014

How to cite: Tokuda A. M. P., Peres, W. S., \& Andrêo, C. (2016). Family, gender and psychosocial emancipation. Psicologia: Ciência e Profissão, 36(4): 921-931. doi: 10.1590/1982-3703001022014

Cómo citar: Tokuda A. M. P., Peres, W. S., \& Andrêo, C. (2016). Familia, género y la emancipación psicosocial. Psicologia: Ciência e Profissão, 36(4): 921-931. doi: 10.1590/1982-3703001022014 